\title{
A Practitioners' Point Of View On How Digital Innovation Will Shape The Future Of Business Process Management: Towards A Research Agenda.
}

\author{
Amy Van Looy \\ Ghent University, EB24 \\ Amy.VanLooy@UGent.be
}

\author{
Geert Poels \\ Ghent University, EB24 \\ Geert.Poels@UGent.be
}

\begin{abstract}
While the benefits of digital innovation are compelling (e.g. economic growth and productivity), the often disruptive and unpredictable character of new IT gives us food for thought on how digital innovation can be applied to an organization's business processes. Since the link between Business Process Management (BPM) and digital innovation is still under-investigated, this article helps advancing the field by exploring how practitioners see the future of BPM evolve in a digital economy. Based on an expert panel of 19 West-European managers and consultants, we identified seven expected trends in BPM practices affected by digital innovation. Research opportunities are derived from these trends and attributed to the research traditions within the BPM discipline. The resulting research agenda can be an input for academics and, based on their research, provide beneficial aspects for industry. Moreover, this article sensitizes business executives to potential investments and practical challenges of digitalization in the workplace.
\end{abstract}

\section{Introduction}

Organizations can strategically apply Business Process Management (BPM) for diverse reasons such as operational excellence, product/service leadership and customer intimacy $[12,25]$. New IT trends like Artificial Intelligence, Virtual Reality, Internet of Things (IoT) and blockchain have a disruptive impact on organizations and their business processes, influencing everyone's private life as customers and professional life as employees. It is expected that we will increasingly interact with robots as virtual personal assistants on smartphones or as online helpdesks [1]. Gartner [2] predicts that about 100 million customers will shop in augmented reality by 2020. Regarding one's professional life, McKinsey [3] states that jobs will rely more on man-machine collaboration while executing business processes by 2030.

Innovation requires investments that pay off. First, new technologies may help tackle the increasing global consumption; a growth that McKinsey [3] estimates at $\$ 23$ trillion between 2015 and 2030. Secondly, new IT can offer higher employee performance [2]. According to Gartner [1], "through 2019, every \$1 enterprises invest in innovation will require an additional $\$ 7$ in core execution", and "by 2022, IoT will save consumers and businesses \$1 trillion a year in maintenance, services and consumables". Also the forecasted financial merits of new IT are high. Gartner estimates that a blockchain-based business is worth $\$ 10$ billion [1], and positions human augmentation technology as a multi-billion dollar market [2].

However, new technologies require new skills and lifelong learning. Intelligent automation (i.e. the combination of robotics and artificial intelligence) will eliminate lower-skill, mid-level and high-skill jobs in the near future. But technology will also create new job types and reemployment of displaced workers $[4,5]$, involving more social, emotional or advanced cognitive activities that machines are less capable of [3]. Given the expected workforce transitions in the near future [3], there is call for learning organizations and digitalization in education programs in order for (future) employees to become more familiar with IT and continue to guarantee the execution of business processes and interaction with end customers [6, 7].

In contrast to these practical needs is a paucity of information about the way in which the BPM discipline should cope with the above-mentioned opportunities or challenges [23, 47, 48]. The BPM body of knowledge offers multiple research agendas for various topics, among others an exemplar process mining agenda [8]. Nonetheless, the link between BPM and digital innovation (DI) is still under-investigated (gap 1). Moreover, most agenda-setting contributions are written by identifying research gaps in a literature review or from the researchers' personal opinion and expertise (gap 2). Instead, our objective is to present a practice-based BPM-DI research agenda as a useful 
starting point for obtaining applicable means that advance the critical BPM-DI integration. This paper reports on expected trends as experienced by practitioners who combine BPM and digital innovation in their daily work. We therefore constituted an expert panel of 19 West-European BPM managers, digital innovation/transformation managers and IT consultants working on both BPM and digital innovation. As a result, this paper launches a call for more research on the combination of BPM and digital innovation, and illustrates this call by proposing some illustrative research avenues across the two research traditions on information systems (IS) and on management within the BPM discipline [12, 25].

The remainder is structured as follows. Section 2 starts with the research background. Next, our expert panel approach is described in section 3. The resulting trends are presented in section 4, followed by a practitioner-based research agenda in section 5 .

\section{Research background}

We first look at prior agenda-setting contributions in the BPM field, before the link is made to DI.

\subsection{BPM research agenda-setting}

While much literature exists on innovation management and BPM separately, a research agenda that relates BPM with DI does not yet exist. Having a look at other agenda-setting contributions is a useful starting point to get familiar with their research methods or agenda-setting approach. We focused on BPM studies to have a narrow scope, and particularly looked for articles using the topic keywords "process management" and "research agenda" in the Web of Science (unlimited in time; given the few search matches) and Google Scholar (as from 2014; to include only recent agendas) until February 2018 (Table 1). We deliberately did not repeat the exercise for innovation research agendas, since our emphasis is on BPM research considering DI without intending to provide a systematic literature review of all keywords.

Besides the fact that no agenda-setting article was found regarding the general link between BPM and DI (gap 1), most articles in Table 1 except for [12] and [14] seem to ignore a practitioner-related point of view (gap 2). Nonetheless, a research agenda should have both scientific and practical relevance. In order to have practical relevance, research avenues should not only attract academic interest but also provide beneficial aspects for industry. Hence, both academics and practitioners are ideally involved when developing and evaluating a research agenda.
Table 1. An overview of existing studies including a BPM research agenda.

\begin{tabular}{|c|c|c|c|}
\hline Source & Publication & Topic & Approach \\
\hline [8] & Journal & $\begin{array}{l}\text { Process } \\
\text { mining }\end{array}$ & $\begin{array}{l}\text { Literature review, } \\
\text { researchers' } \\
\text { expertise }\end{array}$ \\
\hline [9] & Conference & $\begin{array}{l}\text { Autonomous } \\
\text { BPM }\end{array}$ & $\begin{array}{l}\text { Literature review, } \\
\text { researchers' } \\
\text { expertise }\end{array}$ \\
\hline [10] & Journal & Link to culture & Literature review \\
\hline [11] & Journal & $\begin{array}{l}\text { BPM in } \\
\text { general }\end{array}$ & $\begin{array}{l}\text { Literature review, } \\
\text { researcher's } \\
\text { expertise }\end{array}$ \\
\hline [12] & Journal & $\begin{array}{l}\text { BPM in } \\
\text { general }\end{array}$ & $\begin{array}{l}\text { Literature review, } \\
\text { focus groups: } \\
\text { experts from } \\
\text { academia and } \\
\text { practice }\end{array}$ \\
\hline [13] & Conference & $\begin{array}{l}\text { Process } \\
\text { models and } \\
\text { business rules }\end{array}$ & Literature review \\
\hline [14] & $\begin{array}{l}\text { Book } \\
\text { chapter }\end{array}$ & $\begin{array}{l}\text { Collaborative } \\
\text { green BPM }\end{array}$ & $\begin{array}{l}\text { Action-based } \\
\text { research }\end{array}$ \\
\hline [15] & Conference & $\begin{array}{l}\text { BPM in } \\
\text { general }\end{array}$ & $\begin{array}{l}\text { Literature review, } \\
\text { researchers' } \\
\text { expertise }\end{array}$ \\
\hline [16] & Journal & $\begin{array}{l}\text { BPM in } \\
\text { general }\end{array}$ & $\begin{array}{l}\text { Literature review, } \\
\text { researchers' } \\
\text { expertise }\end{array}$ \\
\hline [17] & Journal & $\begin{array}{l}\text { Process } \\
\text { improvement }\end{array}$ & $\begin{array}{l}\text { Literature review, } \\
\text { researchers' } \\
\text { expertise }\end{array}$ \\
\hline [18] & Journal & BPM training & Literature review \\
\hline
\end{tabular}

However, different reasons exist for excluding practitioners in the academic discourse [45, 46]: when business people and academics have a different view of knowledge (e.g. prescriptive versus reflexive needs) [46], when assuming that practitioners are unable to assess the value of research methods and evidence [45] or assuming that current management practice is not based on the latest scientific theory [45], among others due to poor dissemination of research findings [46].

In response, the current paper will provide a practitioners' point of view on BPM needs in a digital economy, without pretending to offer a comprehensive research agenda based on an extensive literature review. Instead, this point of view is an important first step since BPM and DI require a certain level of practical comprehension or experience, and should help address business problems. Although quantitative and case studies have been published on the relevance of a BPM-DI integration [48, 51], more useful research is needed to advance in academia and business. 


\subsection{Digital innovation}

Digital innovation is "a product, process, or business model that is perceived as new, requires some significant changes on the part of adopters, and is embodied in or enabled by IT' [7: p. 330]. Innovation needs a combination of user desirability, business viability and technology feasibility [19]. These three aspects can be considered in a business model (e.g. a business canvas with different perspectives to be considered), as is done in a Lean start-up [20]. Alternatively, organizations can start from a problem for which a solution is needed, without an initial business case, as is done by design thinking [19].

Since top management support is crucial for DI, [21] argue that leaders should foster a culture tolerant of failure and embrace four behaviors: (1) be clear about priorities, (2) provide effective two-way feedback, (3) recognize staff and support risk-taking, and (4) engage in development conversations. These authors state that the success of a digital transformation depends on risk-taking, communication, and tolerance towards failure [21]. More specifically, [22] differentiated three types of chief digital officer (CDO): (1) digital accelerators focusing on DI, (2) digital marketers emphasizing data analytics, and (3) digital harmonizers with eye for customer engagement.

\subsection{BPM and digital innovation}

In the context of BPM, DI pertains both to the ITenabled innovation of business processes performed to produce outcomes (i.e. process innovation) and the innovation of the process outcomes themselves (i.e. product/service innovation). [23] assert that BPM can benefit from DI to achieve faster, more efficient and innovative business processes, and to better deal with data and unstructured business processes. On the other hand, [24] showed that process orientation positively influences organizational innovation performance, e.g. by means of an increased customer focus. This means that BPM can also enable DI when looking for optimization opportunities, instead of merely being the subject of DI when applying digital technologies for process execution [25].

As a result, the BPM discipline started recognizing DI assets in terms of BPM strategies. For instance, the focus on value creation for end customers is inherently included in approaches such as value-driven BPM [25, 26] and customer process management [26]. Also the notion of ambidextrous BPM gains importance to proactively explore new innovation opportunities instead of merely exploiting existing BPM methods and techniques [26]. [27] express the impact of new IT by differentiating between intelligent BPM, collaboration BPM and case-driven BPM. To support this growing awareness of the linkage between BPM and DI, [28] call for more research on the integration of BPM and IT management to facilitate process innovation and IT-enabled business value delivery.

\section{Methodology}

For the purpose of our research, we opted for an expert panel approach [29, 30], involving practitioners with experience in both BPM and DI. Individual interviews were conducted with each of the experts to avoid group pressure. The experts could rely on their entire career instead of being limited to their current organization in order to enrich the data.

Table 2. The experts' profile $(\mathrm{N}=19)$.

\begin{tabular}{l|l|l|l}
\hline Expert ID & $\begin{array}{l}\text { Years of } \\
\text { experience } \\
\text { in BPM }\end{array}$ & $\begin{array}{l}\text { Years of } \\
\text { experience } \\
\text { in DI }\end{array}$ & $\begin{array}{l}\text { Sectors of } \\
\text { experience [NACE } \\
\text { codes] }\end{array}$ \\
\hline Expert A & 15 & 5 & $\mathrm{C}$ \\
\hline Expert B & 4 & 4 & E, J, Q \\
\hline Expert C & 10 & 3 & $\mathrm{C}, \mathrm{G}, \mathrm{H}, \mathrm{J}$ \\
\hline Expert D & 20 & 5 & $\mathrm{C}, \mathrm{M}$ \\
\hline Expert E & 20 & 13 & $\mathrm{C}, \mathrm{J}, \mathrm{K}$ \\
\hline Expert F & 10 & 5 & $\mathrm{~J}$ \\
\hline Expert G & 15 & 15 & $\mathrm{~A}, \mathrm{C}, \mathrm{J}, \mathrm{O}, \mathrm{Q}$ \\
\hline Expert H & 12 & 6 & $\mathrm{C}, \mathrm{H}, \mathrm{O}, \mathrm{R}, \mathrm{S}$ \\
\hline Expert I & 12 & 12 & $\mathrm{E}, \mathrm{H}, \mathrm{J}, \mathrm{N}$ \\
\hline Expert J & 7 & 7 & $\mathrm{~J}$ \\
\hline Expert K & 20 & 10 & $\mathrm{~J}$ \\
\hline Expert L & 8 & 3 & $\mathrm{G}, \mathrm{N}$ \\
\hline Expert M & 1 & 30 & $\mathrm{C}, \mathrm{J}$ \\
\hline Expert N & 10 & 10 & $\mathrm{E}, \mathrm{K}, \mathrm{O}$ \\
\hline Expert O & 17 & 17 & $\mathrm{C}, \mathrm{D}, \mathrm{J}, \mathrm{R}$ \\
\hline Expert P & 20 & 6 & $\mathrm{C}, \mathrm{G}, \mathrm{J}$ \\
\hline Expert Q & 7 & 5 & $\mathrm{C}, \mathrm{J}, \mathrm{K}$ \\
\hline Expert R & 5 & 3 & $\mathrm{C}$ \\
\hline Expert S & 6 & 6 & $\mathrm{~J}, \mathrm{P}$ \\
\hline & & &
\end{tabular}

Nineteen West-European practitioners were interviewed face-to-face during November 2017. The experts were selected from the first author's professional network and via LinkedIn, based on their role as BPM manager, digital innovation/transformation manager or IT consultant with experience in both BPM and DI. This selection allowed us to compose a broad and relevant expert panel (Table 2), covering multiple perspectives from BPM and digital innovation/transformation to obtain some degree of data triangulation [31]. Multiple industry/service sectors were covered, and the years of experience in BPM or DI ranged up to 30 years. We 
ended up with a reasonable response rate of $22.35 \%$ and a panel size larger than the absolute minimum of twelve experts required for data saturation [32,33].

This paper reports on a final question of the onehour, semi-structured interviews: "How do you see the interchanging role of BPM and digital innovation evolving in the (near) future? Why?" Familiarity with the topic was guaranteed by $1 /$ the previous interview questions, and 2/ orally explaining the DI definition [7] to ensure a common understanding. Coding was inductive and followed the coding process of [34]. This means that initial nodes were created to resemble the answered ideas, which were then aggregated in higherlevel nodes to find categories or themes in Nvivo.

Regarding reliability, the study profits from investigator triangulation [35] by means of one researcher coordinator and 59 Master students in IT management. Each expert was interviewed by a group of circa five students who participated in a curriculumbased research project. The interview transcripts were analyzed by all student groups separately, and then peer reviewed. The main researcher double-checked the student results, and performed the coding in parallel. Measurement validity was addressed by regularly summarizing an expert's answers during the interview, and by asking additional questions to obtain face validity. Nvivo facilitated our coding efforts. Internal validity was ensured by an interview protocol that prescribed how the Master students should conduct and analyze the interviews. External validity, however, remains limited to the covered sectors in West-Europe.

\section{Results}

The experts expect that DI will affect an organization's BPM practices by means of seven trends (Table 3). These trends were distilled by interpreting the Nvivo analysis results of the expert interviews.

\subsection{Ever changing customer experience}

The experts unanimously agreed that the synergies between BPM and DI will result in a changing end customer experience. Besides the recognition that end customers are key, customer expectations will also frequently change (ExpE) while DI offers new possibilities for customer differentiation (ExpD, ExpE, ExpI, ExpO, ExpS). Organizations should also pay attention to the increasing impact of online customer reviews $(\mathrm{ExpH})$. In response, organizations will have to work with a more varied team to think in terms of end customers (ExpK), and involve employees, customers and other stakeholders by means of cocreation initiatives (ExpJ). ExpF added that "customers
Table 3. An overview of expected DI trends in BPM, according to the expert panel ( $\mathrm{N}=19)$.

\begin{tabular}{l|c|l}
\hline Trend & $\begin{array}{l}\text { Expert } \\
\text { count }\end{array}$ & Expert IDs \\
\hline $\begin{array}{l}\text { 1/ Ever changing customer } \\
\text { experience }\end{array}$ & 19 & $\begin{array}{l}\text { A, B, C, D, E, F, G, } \\
\text { H, I, J, K, L, M, N, } \\
\text { O, P, Q, R, S }\end{array}$ \\
\hline $\begin{array}{l}\text { 2/ Stronger strategic link } \\
\text { between BPM and digital } \\
\text { innovation }\end{array}$ & 16 & $\begin{array}{l}\text { A, B, C, D, E, F, G, } \\
\text { H, I, J, L, M, N, O, } \\
\text { Q, R }\end{array}$ \\
\hline $\begin{array}{l}\text { 3/ Faster innovations, } \\
\text { process changes, way of } \\
\text { working }\end{array}$ & 16 & $\begin{array}{l}\text { A, B, C, D, E, F, G, I, } \\
\text { K, L, M, N, O, Q, R, } \\
\text { 4/ Increasing need for } \\
\text { business-IT alignment }\end{array}$ \\
\hline $\begin{array}{l}\text { 5/ New CxO role to bring } \\
\text { BPM and DI to the Board }\end{array}$ & 15 & $\begin{array}{l}\text { A, B, C, F, G, H, I, J, } \\
\text { K, M, N, O, P, Q, S }\end{array}$ \\
\hline $\begin{array}{l}\text { 6/ BPM becomes more } \\
\text { sexy (e.g. process } \\
\text { modeling, monitoring) }\end{array}$ & 6 & $\begin{array}{l}\text { A, C, D, E, F, G, H, } \\
\text { L, N, P, S }\end{array}$ \\
\hline $\begin{array}{l}\text { 7/ Less resistance to BPM } \\
\text { and digital innovation }\end{array}$ & 6 & C, F, M, K, L, Q \\
\hline
\end{tabular}

will be better informed about process instances due to advanced monitoring".

While all experts confirmed the increasing role of digital technologies in customer experience, some explicitly referred to specific types of new IT that will trigger a tremendous change in customer experience while executing business processes, such as: Artificial Intelligence (3 experts), big data and data analytics ( 2 experts), blockchain and bitcoins (2 experts), robotics ( 2 experts), cloud ( 1 expert), Virtual Reality (1 expert), mobile, ( 1 expert), IoT and sensors for proactive handling and maintenance (1 expert). ExpG also mentioned a shift from Industry 3.0 (e.g. ERP, CRM, BI) to Industry 4.0 which focuses more on data, e.g. by means of Robotic Process Automation and AI.

\subsection{Stronger strategic link between BPM and digital innovation}

All experts agreed that a strategic link exists between BPM and DI, and that IT enables the realization of process and business strategies. While some experts merely stated that this link will continue to exist, ExpQ mentioned that "more synergies between BPM and DI are to be expected since BPM profiles will acquire more experience with DI". ExpO confirmed that the BPM-DI relationship "will have an even more strategic role and impact on disruptive business models, and so creating more synergies between BPM and DI'. Both BPM and DI require a strategic vision with clear leadership and employee coaching (ExpB, ExpO). In general, ExpL and ExpH 
summarized that process changes will always depend on the IT possibilities at a certain moment in time, and that there are more and more opportunities to change business processes. Eight experts referred to specific types of new IT to illustrate those new opportunities for process innovations.

\subsection{Faster innovations, process changes, way of working}

Sixteen out of 19 experts saw a tremendous impact of doing things faster, given the fast emergence of new IT. This accounts not only for faster process innovations, but also for faster incremental process changes and faster process executions, thus affecting an organization's entire way of working. As a result, BPM should become more pragmatic by means of experiments and pilots, while the entire process lifecycle should turn into more iterative, agile or shorter cycles. ExpB explained that this trend will evolve since DI will only go faster. Also ExpQ was convinced that the reasons for faster process changes are more incremental testing, pilot processes, and trials for testing new things. ExpG, ExpK and ExpN generalized that new IT and DI will only increase in speed, and thus affecting all organizations to some extent. There is also a need for faster management of changes and more flexibility in problem-solving (ExpC, ExpE). For instance, ExpD, ExpI and ExpO explained that flatter organizations allow for faster decision-making and empowerment. Finally, ExpJ gave an interesting comment that "BPM will not only become faster, but also cheaper because of less bureaucracy".

\subsection{Increasing need for business-IT alignment}

Fifteen out of 19 experts expressed the need for a stronger business-IT alignment. Business-IT alignment problems are currently experienced not only by process owners but also by other employees and the Board. Since IT enables the realization of process and business strategies (ExpA, ExpG), finding a fit with the corporate strategy to assess potential IT solutions is crucial (ExpB). Moreover, "IT will get an increasing role by offering new ways to monitor, measure and document a business process" (ExpQ), which emphasizes the need for proper business-IT alignment and requiring a good IT architecture.

Two experts added that the increasing strategic link (trend 2) between BPM and DI will also trigger more IT governance concerns (e.g. privacy and security issues) for the use of operational tools. ExpB explained that "privacy issues will become stricter, but can still be bypassed internationally". Regarding possible security issues, ExpC argued that a good balance should be found between offline and online work, for instance, "organizations are increasingly dependent on the Internet, e.g. by working in clouds or by means of IoT. This also means that business life can be paralyzed when access to the Internet is temporarily broken". Hence, organizations should be strategically prepared to overcome such work losses and ensure business continuity.

\subsection{New $\mathrm{CxO}$ role to bring $\mathrm{BPM}$ and digital innovation to the Board}

While all experts agreed on the importance of top management support for BPM and DI, eleven experts stipulated the importance of a $\mathrm{CxO}$ role responsible for both BPM and DI, who directly reports to the CEO. Such a formal role will not only serve as a believer or sponsor of BPM/DI projects, but also facilitates strategic decision-making and communication across departments and business processes. Hence, such a new $\mathrm{CxO}$ role can better translate an organization's intentions towards BPM and DI.

\subsection{BPM becomes more sexy}

All experts recognized to some extent that DI will put more emphasis on the PLAN phase (i.e. business case, process designs) and the CHECK phase (i.e. monitoring) of the process lifecycle. Nonetheless, six out of 19 experts stated that BPM is still frequently perceived as unsexy by many non-expert practitioners (e.g. by seeing BPM as boring engineering stuff with complex flows), although organizations acknowledge BPM's overall relevance. These six experts were also of the opinion that DI can make BPM more attractive for a wider audience. For instance, ExpK explained that "process modeling will evolve in the near future to journey mapping like in a comic book instead of brown papers and post-its, but process modelling can also be done using video apps". ExpQ confirmed that organizations should focus more on faster ways for process modeling to let process change prevail. Similarly, ExpE warned that "Artificial Intelligence can make business processes too complex to be modelled in regular process diagrams". Finally, DI will also affect process monitoring. ExpF asserted that organizations should focus more on process monitoring to achieve faster reactions, while ExpL explained that DI will help capture more data for process monitoring resulting in a more advanced process analysis. 


\subsection{Less resistance to BPM and digital innovation}

Strikingly, all experts referred to some degree of resistance to BPM and DI among all operational and managerial levels, and the increasing need for change management. While most experts refined this idea by stating that resistance to change is people-dependent, three experts predicted that the future will bring less resistance to process innovation and process change. Particularly, ExpM and ExpO predicted that DI will become the new normal in organizations. Also ExpS argued that "more visibility of success stories will lead to employees being more familiarized with DI and BPM thinking, and thus leading to less resistance".

As another reason for less resistance, five out of 19 experts explicitly emphasized the need for changing job contents and education programs. Three experts $(\mathrm{ExpC}, \mathrm{ExpF}$ and $\mathrm{ExpO})$ elaborated on the aspect of automation that necessarily leads to different job contents and job descriptions. According to ExpM and ExpN, digitalization will also become more central in normal education programs and employees will gain more education budgets by their employers.

\section{Discussion}

Based on the expected trends in BPM practices, uncovered in Section 4, some practical guidelines can be considered pending further investigation.

Table 4. Preliminary guidelines for executives.

\begin{tabular}{l|l}
\hline Trend & Practical guideline \\
\hline 1 & $\begin{array}{l}\text { Customers will be more included when linking } \\
\text { BPM-DI by co-creation \& customer differentiation }\end{array}$ \\
\hline 2 & $\begin{array}{l}\text { Strategic thinking and return-on-investment will } \\
\text { become more important }\end{array}$ \\
\hline 3 & $\begin{array}{l}\text { Employees will be more involved in trial-and-error } \\
\text { problem-solving }\end{array}$ \\
\hline 4 & $\begin{array}{l}\text { The BPM techniques will become more complex } \\
\text { with the advancements in DI }\end{array}$ \\
\hline 5 & $\begin{array}{l}\text { The BPM-DI link will create a greater awareness to } \\
\text { IT governance in an organization }\end{array}$ \\
\hline 7 & $\begin{array}{l}\text { Focus more on story-telling for process modeling } \\
\text { and data-driven decision-making for monitoring }\end{array}$ \\
\hline & $\begin{array}{l}\text { Since DI change is more drastic, managing change } \\
\text { will increase in importance within BPM }\end{array}$ \\
\hline
\end{tabular}

We now derive corresponding research avenues by differentiating between IS-related and managementrelated avenues in order to address BPM as a holistic discipline and to better categorize the topics along the BPM research traditions $[12,25]$.

\subsection{Research agenda for the IS-related aspects of BPM}

Research on the IS-related aspects of BPM can focus on foundational and/or engineering approaches. Foundational research investigates BPM systems, methods, algorithms and architectures using computer science research, while engineering research within the BPM discipline focuses more on technical artifacts and prototypes in line with design-science research (DSR) and information systems engineering. Table 4 suggests how computer science research and engineering research can contribute to the seven DI trends that were uncovered by our expert panel.

\section{Table 5. Possible IS-related avenues in BPM.}

\begin{tabular}{|c|c|}
\hline Trend & $\begin{array}{l}\text { IS-related aspects of BPM } \\
\text { “More research on": }\end{array}$ \\
\hline 1 & $\begin{array}{l}\text { - Methods and techniques for } \\
\text { intelligent/collaboration/case-driven BPM to } \\
\text { proactively meet changing customer needs } \\
\text { - How to use customer data (e.g., expectations, } \\
\text { performance perceptions, satisfaction) in } \\
\text { diagnostic/predictive/prescriptive process } \\
\text { analytics }\end{array}$ \\
\hline 2 & $\begin{array}{l}\text { - Explorative methods and techniques } \\
\text { (ambidextrous BPM) } \\
\text { - The strategic use of new IT to improve process } \\
\text { efficiency and effectiveness }\end{array}$ \\
\hline 3 & $\begin{array}{l}\text { - Methods and techniques for faster BPM cycles } \\
\text { - Applying agile principles to BPM (agile BPM) }\end{array}$ \\
\hline 4 & $\begin{array}{l}\text { - How to integrate the process architecture into the } \\
\text { overall enterprise architecture with application } \\
\text { and technical architectures that embrace new IT } \\
\text { - Collaboration platforms per process lifecycle } \\
\text { stage }\end{array}$ \\
\hline 5 & - Less applicable \\
\hline 6 & $\begin{array}{l}\text { - Process modelling alternatives (e.g. journey } \\
\text { mapping via comic books and video apps) } \\
\text { - How process monitoring tools can become more } \\
\text { approachable for a wider (non-expert) audience } \\
\text { (e.g. dashboards and tableaux techniques) } \\
\text { - Tools supporting case-driven BPM and } \\
\text { knowledge-intensive/unstructured processes } \\
\text { - Monitoring tools for intelligent BPM }\end{array}$ \\
\hline 7 & $\begin{array}{l}\text { - How to use employee data (e.g., job satisfaction, } \\
\text { perceived work difficulty, stress) in } \\
\text { diagnostic/predictive/prescriptive process } \\
\text { analytics } \\
\text { - User-friendly artifacts (e.g. evaluation criteria) to } \\
\text { be accessible to non-experts }\end{array}$ \\
\hline
\end{tabular}

First, regarding the computer science focus in BPM, systems research (i.e. the traditional home ground of business process research) is increasingly 
integrating with data research. Data research in computer science has benefited more from technological breakthroughs than engineering research. Increasingly, data research topics like data mining, machine learning, data analytics and big data have found their way in BPM research. Advancement in foundational BPM research (e.g. process mining, process execution monitoring and prediction) has been enabled through the rise of Data Science, which itself relies strongly on the increased technological capacity to capture/store/analyze massive volumes of data. Accordingly, this stream of BPM research has seen an increasing use of diagnostic/predictive/prescriptive analytical techniques (e.g. trend 6, trend 7), being incorporated into BPM systems, methods and algorithms, where the underlying technological big data management platforms become integrated into the process management architecture (e.g. trend 4). The integration of data research into foundational BPM research has become known as smart BPM, a term that gained popularity with the special issue in Decision Support Systems of 2017 [36].

Our experts expect to see more applications of smart BPM in the near future (i.e. all trends, except for trend 5), leveraging new methods and techniques of Data Science. For instance, whereas the currently captured and analyzed process data is highly structured (i.e. event $\operatorname{logs}$ ), static (i.e. historic data on process execution do not change), and generally of high quality (i.e. mostly assumed to be complete and consistent), big data analytics can deal with data of varying degrees of structure, flexibility, and quality (e.g. trend 6). This would allow for integrating highly structured and fixed process performance data with less structured and less fixed data. Examples are perceived waiting and execution times or overall process satisfaction data obtained from customer surveys or through sentiment analysis of social media data (e.g. company/product/service discussion groups) (e.g. trend 1). Also process worker data could be captured more and integrated into the process data lakes (e.g. job satisfaction, perceived difficulty of process efficiency, task complexity, stress) (e.g. trend 7).

Secondly, regarding the engineering focus in BPM, practitioners need more design-based research (i.e. applying DSR) that creates new BPM technical artifacts or improves existing ones by making use of novel digital technologies (e.g. process infrastructures, BPM systems or tools that provide data-driven recommendations for process execution), and so contributing to 'design and action' theories in the BPM discipline [37]. Technologies like Internet of Things (IoT), intelligent automation and blockchain will become a standard component of many kinds of process infrastructures. E.g., including IoT devices in the process infrastructure will facilitate a more transparent real-time data capture, which can be used advantageously for directing and coordinating process execution as well as for monitoring and process mining (e.g. trend 6). Blockchain applications have the potential to make business processes more efficient, less costly, more secure and more transparent, although more research is needed to find out if these benefits really hold [38], in particular whether benefits are scalable. Supporting human process workers by AIcontrolled robots (e.g. front-office workers, helpdesk employees) is no science-fiction. More of such innovations are expected by our expert panel to increase process efficiency and effectiveness (e.g. trend 2, trend 3 and trend 7). The consideration of novel technologies in engineering BPM research may also attract the attention of young technology-savvy researchers, and bring new blood into the BPM research community. The community is becoming increasingly aware of research opportunities on the edge of DI and BPM, e.g. mini tracks like "Digital innovation", "Business value of smart devices on IoT", "The impact of digitalization on business operations" and "The transformational impact of blockchain" within the main track for "Organizational systems and technology" at HICSS.

\subsection{Research agenda for the management- related aspects of BPM}

The management tradition of BPM is especially interested in a better understanding of BPM and the strategic and managerial issues related to BPM and DI. Most of the expected trends revealed by our panel can be linked to this tradition (Table 5), and confirm that BPM is a holistic discipline [12] that needs to reach out more to other management disciplines.

For instance, the experts indirectly referred to aspects regarding quality management and performance management (e.g. trend 1), strategic management (e.g. trend 2), project management (e.g. trend 3 , trend 6), change management (e.g. trend 7), people management and human resources management (e.g. trend 1), and IT governance (e.g. trend 4 and trend $5)$. Theories and frameworks from other management disciplines can be used to further theorize about BPM and help underpin BPM, which is still a rather atheoretical discipline [39]. Such BPM-related theories will mainly cope with 'analysis' theories and theories to 'explain' and/or 'predict' BPM phenomena [37] by considering an organization's business environment in case studies or surveys. Consequently, BPM can escape from its narrow, distinct boundaries to become a more recognized perspective in the broader debates 
on organizational behavior [40], which is paramount since business processes are present in all organizations and refer to the work that needs to be done to create business value. This means that BPM should go back to its management roots in order to become fully part of management frameworks, as is already done in quality labels (e.g. ISO-9001 https://www.iso.org/iso-9001-quality-

management.html or EFQM http://www.efqm.org/) or in the Balanced Scorecard approach $[41,42]$ in which process performance is officially recognized as one out of four business performance perspectives.

Besides holism, the experts also mentioned aspects that can broaden the BPM principles [12] to a DI context, such as context-awareness (all trends to some extent), continuity (trend 2, trend 3, trend 7), enablement (trend 2, trend 3, trend 6), institutionalization (trend 5), involvement (trend 1), joint understanding (trend 6), purpose (trend 2), simplicity (trend 3, trend 6) and technology appropriation (trend 4 ).

Table 6. Possible management-related avenues in BPM.

\begin{tabular}{l|l}
\hline Trend & $\begin{array}{l}\text { Management-related aspects of BPM } \\
\text { "More research on": }\end{array}$ \\
\hline 1 & $\begin{array}{l}\text { - Co-creation of process value with end customers } \\
\text { - The realization of process-oriented values like } \\
\text { customer understanding and experience (Customer } \\
\text { Process Management) }\end{array}$ \\
\hline 2 & $\begin{array}{l}\text { - BPM critical success factors from a DI perspective } \\
\text { - Strategic alignment between BPM and DI (value- } \\
\text { driven BPM) } \\
\text { - Disruptive business models and the impact on BPM } \\
\text { - Guidelines for balancing an exploitative and } \\
\text { explorative approach (ambidextrous BPM) }\end{array}$ \\
\hline 3 & $\begin{array}{l}\text { - Studying and improving the process of DI } \\
\text { - Time management and project management for } \\
\text { process owners } \\
\text { - Maturity models facilitating a BPM-DI adoption }\end{array}$ \\
\hline 4 & $\begin{array}{l}\text { - The degree to which traditional business-IT } \\
\text { alignment models apply to a DI context }\end{array}$ \\
\hline 5 & $\begin{array}{l}\text { - BPM governance, and the sometimes conflicting } \\
\text { roles of Chief Operations/Process managers, Chief } \\
\text { Information managers and Chief Innovation } \\
\text { managers }\end{array}$ \\
\hline 6 & $\begin{array}{l}\text { - Best practices and success stories to share } \\
\text { knowledge and find BPM-DI advocates }\end{array}$ \\
& $\begin{array}{l}\text { How change management models and techniques } \\
\text { offer best practices for BPM } \\
\text { New curricula in IT and BPM management and innovation can be taught to } \\
\text { kids as from primary school }\end{array}$ \\
\hline 6 &
\end{tabular}

Table 5 presents some practically justified research avenues after exploring how practitioners see the future of BPM evolve in a digital economy. To our knowledge, some of them have already been touched in preliminary studies, such as trend 1 [49], trend 2 [50], trend 5 [22] and trend 6 [51], which open the way to more future-proof research.

\section{Conclusion}

Since a practitioner's point of view is frequently neglected in research agendas, we provide seven trends expected by West-European practitioners who combine BPM with DI in their daily work. The trends illustrate how BPM practices can become more ingrained by DI, and serve as an input to distill highly practical studies (gap 1) that supplement more comprehensive BPM research agendas by practical motivations (gap 2).

As an illustration of its potential use, this article has proposed some future research avenues across two research traditions (i.e. on IS and on management) within the BPM discipline, and related them to emerging BPM strategies such as intelligent or smart BPM [27, 36], collaboration BPM [27], and casedriven BPM [27] for particularly the IS tradition of BPM, whereas value-driven BPM [25, 26], customer process management [26], and ambidextrous BPM [26] were mostly linked to the management tradition of BPM. Also agile BPM [43, 44] was highlighted in our findings to shorten the traditional lifecycle through which each business process evolves. The emerging strategies are linked to the trends as follows:

- Trend 1 (changing customer experience): smart/intelligent BPM, collaboration BPM, casedriven BPM, customer process management

- Trend 2 (stronger strategic link): value-driven BPM and ambidextrous BPM

- Trend 3 (working faster): agile BPM

- Trend 4 (more business-IT alignment): collaboration BPM

- Trend 5 (new $\mathrm{CxO}$ role): value-driven BPM and ambidextrous BPM

- Trend 6 (BPM becomes more sexy): smart/intelligent BPM, collaboration BPM

- Trend 7 (less resistance to BPM and DI): collaboration BPM and customer process management

Although we acknowledge limitations related to our panel size and composition (e.g. geography), we intend to stimulate a discussion about the evolution of BPM in a digital economy based on hypothetical trends. We feed this discussion by including the BPM and DI practitioner's perspective on what can be expected in the near future. This article thus takes the perspective 
that practice can guide theory to strengthen the link between academic quality and practical relevance [45, 46], and to better justify research.

In future work, our preliminary findings give rise to two avenues. First, a conceptual avenue can deepen the research agenda by conducting a systematic literature review of BPM and DI based on extant studies (i.e. theoretical, empirical and conceptual research) to clarify the gaps in what we know from the literature and what we need to know in the future. Secondly, a practical avenue may advise business executives on how to simultaneously pursue BPM and DI in order to solve business problems. Aspects to be considered are the background differences among panel experts (i.e. roles, sectors) or the DI types, aiming to investigate how organizations can take different approaches in achieving the BPM-DI synthesis. Hence, a practical framework can be built that categorizes organizations and outlines guidelines per organization type.

\section{References}

[1] Gartner: Gartner predicts a virtual world of exponential change (2016). https://www.gartner.com/

[2] Gartner: Top trends in the Gartner hype cycle for emerging technologies (2017). https://www.gartner.com/

[3] McKinsey: What the future of work will mean for jobs, skills, and wages (2017). https://www.mckinsey.com/

[4] Posner, B.: How far will robots go? MITSloan Management Review (2017). http://sloanreview.mit.edu/

[5] Roth, C.: By 2022, one in five workers engaged in mostly nonroutine tasks will rely on AI to do their jobs (2017). https://blogs.gartner.com/

[6] European Commission: Digital opportunity traineeships: boosting digital skills on the job (2017). https://ec.europa.eu/

[7] Fichman, R.G., Dos Santos, B.L., Zheng, Z.: Digital innovation as a fundamental and powerful concept in the information systems curriculum. MIS Quarterly, 38(2), 329343 (2014).

[8] van der Aalst, W.M.P, Weijters, A.J.M.M.: Process mining: a research agenda. Computers in Industry, 53(3), 231-244 (2004).

[9] Neubauer, T., Goluch, G., Riedl, B.: A research agenda for autonomous business process management. ARES Proceedings, IEEE, 670-680 (2007).

[10] Grau, C., Moormann, J.: Investigating the relationship between process management and organizational culture: literature review and research agenda. Management and Organizational Studies, 1(2), 1-17 (2014).
[11] Recker, J.: Suggestions for the next wave of BPM research: strengthening the theoretical core and exploring the protective belt. Journal of Information Technology Theory and Application, 15(2), 5-20 (2014).

[12] vom Brocke, J., Schmiedel, T., Recker, J., Trkman, P., Mertens, W., Viaene, S.: Ten principles of good business process management. Business Process Management Journal, 20(4), 530-548 (2014).

[13] Wang, W., Indulska, M., Sadiq, S.: Integrated modelling of business process models and business rules: a research agenda. ACIS Proceedings (paper 205), 1-10 (2014).

[14] Jakobi, T., Castelli, N., Nolte, A., Schönau, N., Stevens, G.: Towards collaborative green business process management as a conceptual framework. In: Gómez, J.M. et al. (eds), Advances and New Trends in Environmental and Energy Informatics, 275-293 (2016).

[15] Mendling, J.: From scientific process management to process science. ZEUS Workshop Proceedings, 1-4 (2016).

[16] Recker, J., Mendling, J.: The state of the art of business process management research as published in the BPM conference. Business Information Systems Engineering, 58(1), 55-72 (2016).

[17] Lehnert, M., Linhart, A., Roeglinger, M.: Exploring the intersection of business process improvement and BPM capability development. Business Process Management Journal, 23(2), 275-292 (2017).

[18] Thennakoon, D., Bandara, W., French, E., Mathiesen, P.: What do we know about business process management training? Business Process Management Journal, (preprint) (2018). https://doi.org/10.1108/BPMJ-09-2016-0180

[19] Müller, R.M., Thoring, K.: Design thinking vs. Lean startup. IDMRC Proceedings (p. 151-164) (2012).

[20] Blank, S.: Why the Lean start-up changes everything. Harvard Business Review, 91(5), 65-72 (2013).

[21] Monahan, K., Chmiola, A. Roos, L.: How effective leaders drive digital change. MITSloan Management Review (2017). sloanreview.mit.edu/

[22] Tumbas S., Berente N., vom Brocke J.: Three types of chief digital officers and the reasons organizations adopt the role. MIS Quarterly Executive, 16(2), 121-134 (2017).

[23] Kerpedzhiev, G., König, U., Röglinger, M., Rosemann, M.: Business process management in the digital age (2017). http://www.bptrends.com/

[24] Tang, J., Pee, L.G., Iijima, J.: Investigating the effects of business process orientation on organizational innovation performance. Information \& Management, 50(8), 650-660 (2013). 
[25] Kirchmer, M.: High performance through business process management. Springer, Cham (2017).

[26] Rosemann, M.: Proposals for future BPM research directions. In: Ouyang, C., Jung, J. (eds.) AP-BPM 2014. LNBIP, vol. 181, pp. 1-15. Springer, Cham (2014).

[27] Lederer, M., Knapp, J., Schott, P.: The digital future has many names. ICITM proceedings (p. 22-26) (2017).

[28] Rahimi, R., Moller, C., Hvam, L.: Business process management and IT management: the missing integration. International Journal of Information Management, 36(1), 142-154 (2016).

[29] DiCicco-Bloom, B., Crabtree, B.: The qualitative research interview. Medical Education, 40(4), 314-321 (2006).

[30] Boyce, C., Neale, P.: Conducting in-depth interviews (2006). http://www2.pathfinder.org/

[31] Flick, U.: Triangulation in qualitative research. In: Flick, U., von Kardoff, E., Steinke, I. (Eds). A companion to qualitative research (pp. 178-183). SAGE Publications, London (2004).

[32] Galvin, R.: How many interviews are enough? Journal of Building Engineering, 1(3), 2-12 (2015).

[33] Guest, G., Bunce, A., Johnson, L.: How many interviews are enough? The Field Methods, 18(1), 59-82 (2006).

[34] Saldaña, J.: The coding manual for qualitative researchers. London: SAGE Publications (2016).

[35] Guion, L., Diehl, D., McDonald, D.: Conducting an Indepth Interview, University of Florida (2011) http://edis.ifas.ufl.edu/

[36] Mendling, J., Baesens, B., Bernstein, A., Fellmann, M.: Challenges of smart business process management. Decision Support Systems, 100, 1-5 (2017).

[37] Gregor S.: The nature of theory in information systems. MISQuarterly, 30 (3), 611-642 (2006).

[38] Mendling, J., Weber, I., van der Aalst, W., vom Brocke, J., Cabanillas, C., Daniel, F., Debois, S., Di Ciccio, C., Dumas, M., Dustdar, S., Gal, A., García-Bañuelos, L., Governatori, G., Hull, R., La Rosa, M., Leopold, H., Leymann, F., Recker, J., Reichert, M., Reijers, H.A., Rinderle-Ma, S., Solti, A., Rosemann, M., Schulte, S., Singh, M.P., Slaats, T., Staples, M., Weber, B., Weidlich, M., Weske, M., Xu, X., Zhu, L.: Blockchains for business process management - Challenges and opportunities. ACM Transactions on Management Information Systems, 9(1), 116 (2018).
[39] Trkman, P.: The critical success factors of BPM. International Journal of Information Management, 30, 125134 (2010).

[40] Klun, M., and Trkman, P.: Business process management - at the crossroads. Business Process Management Journal, 24(3), In press (2018).

[41] Van Looy, A., Shafagatova, A.: Business process performance measurement: a structured literature review of indicators, measures and metrics (article number: 1797). SpringerPlus, 5(1), 1-24 (2016).

[42] Kaplan, R.S., Norton, D.P.: The strategy-focused organization. Harvard Business School Press, Boston (2001).

[43] Bruno, G., Dengler, F., Jennings, B., Khalaf, R., Nurcan, S., Prilla, M., Sarini, M., Schmidt, R., Silva, R.: Key challenges for enabling agile BPM with social software. Journal of Software Maintenance and Evolution, 23(4), 297326 (2011).

[44] Thiemich, C., Puhlmann, F.: An agile BPM project methodology. In: Daniel F., Wang J., Weber B. (Eds.) BPM Proceedings. LNCS 8094 (pp. 291-306). Springer, Berlin, Heidelberg (2013).

[45] Baldridge, D. C., Floyd, S. W., \& Markóczy, L. (2004). Are managers from Mars and academicians from Venus? Strategic Management Journal, 25(11), 1063-1074.

[46] Starkey, K., \& Madan, P. (2002). Bridging the Relevance Gap. British Journal of Management, 12(s1), 326.

[47] Schmiedel, T., vom Brocke J.: Business process management. In: vom Brocke J., Schmiedel T. (Eds). BPM Driving Innovation in a Digital World. (pp. 3-15). Springer, Cham (2015).

[48] Van Looy, A.: A quantitative study of the link between business process management and digital innovation. In: Carmona, J., Engels, G., Kumar, A. (Eds.). BPM Forum 2017, LNBIP 297 (pp. 177-192). Switzerland: Springer (2017).

[49] Trkman, P., Mertens, W., Viaene, S., Gemmel, P.: From business process management to customer process management. Business Process Management Journal, 21(2), 250-266 (2015).

[50] Kerpedzhiev, G., König, U., Röglinger, M., Rosemann, M.: Business process management in the digital age (2017). http://www.bptrends.com/

[51] vom Brocke J., Mendling, J.: Business process management cases. Springer, Cham (2018). 